\title{
OTHER FEATURE ARTICLES \\ Broadening Campus Participation in Undergraduate Research through the Office of High-Impact Practices
}

\author{
Michael S. Springer, John F. Barthell, Charlotte K. Simmons, \\ Dana Jackson-Hardwick, Gregory M. Wilson, \\ University of Central Oklahoma
}

\begin{abstract}
The clear and tangible benefits attributed to taking part in undergraduate research and creative experiences are leading colleges and universities to seek ways to broaden participation among students in all academic disciplines, particularly those beyond the STEM fields. The Office of High-Impact Practices was established in 2014 at the University of Central Oklahoma to promote undergraduate research and creative experiences across the university. Its creation, overall description, and successes in broadening participation as well as the steps taken and lessons learned are discussed. The office has led to a broader vision of undergraduate research in the context of other high-impact teaching practices, with increased participation among students in colleges not traditionally represented in large numbers, namely the College of Liberal Arts and College of Fine Arts and Design.
\end{abstract}

Keywords: undergraduate research, high-impact practices, transformative learning, participation, engagement

doi: 10.18833/spur/1/3/10

Undergraduate research experiences that engage students in scholarly and creative work with faculty mentors lead to tangible achievements for students and institutions, including enhanced cognitive and personal development, better research skills, degree programs with added economic value, and improved graduation and retention rates. Undergraduate research—scholarly and creative activities that involve students, working with faculty mentors, in an inquiry, investigation, or project that makes an original intellectual or creative contribution to the discipline-also can deepen students' educational experience, enrich their understanding of disciplinary ways of thinking, build professional relationships with peers and faculty, and boost their interest in graduate studies (Bauer and Bennett 2003; Dean and Kaiser 2010; DeLoach et al. 2012; Kuh 2008; Lopatto 2010; Malachowski et al. 2015). Although STEM disciplines have led the way in engaging students in undergraduate research experiences, students with majors in the fine arts and humanities, academic areas that have been slower to adopt this high-impact practice, can achieve the same rewards (Corley 2013; Dean and Kaiser 2010; DeLoach et al. 2012; DeVries 2001; Ehrenberg 2005; Malachowski 1999; McDorman 2004; Rogers 2003). The challenge faced by many universities, including the University of Central Oklahoma (UCO), is how to broaden engagement in undergraduate research so that students in all disciplines have access to the benefits.

When institutionalizing high-impact practices such as undergraduate research, recognition of potential disciplinary bias (real or perceived) in the administration of these practices is critical, even though the benefits of highimpact practices are potentially unifying across a university campus (Brownell and Swaner 2009). For example, perceived bias toward the sciences has been evidenced by an interpretation of undergraduate research as part of a growing national trend toward STEM-based disciplines and their connection to the workforce. This impression is created at the statewide Oklahoma Research Day (ORD), a conference that is dominated by STEM disciplines (Wohlers et al. 2012). Such biases may be inadvertent, possibly the consequence of inadequate resources for full participation of other disciplines. The wider inclusion of non-STEM disciplines from UCO at the National 
Conference on Undergraduate Research (NCUR), described later in this article, supports this suggestion. Nonetheless, attracting more disciplines also is a consequence of how the activities of the office that oversees them are labeled and conceptualized. It is important that other campuses consider carefully how they communicate about their own organizational structures related to highimpact practices and be as expansive as possible in defining their goals in order to maximize benefits to students and the institution (Gagliardi et al. 2015; Malachowski et al. 2015).

Keeping these points at the forefront, UCO established a faculty-led Office of High-Impact Practices (OHIP) in August 2014 to promote undergraduate research and other transformative learning practices at the institution. Although undergraduate research is only one of Kuh's high-impact educational practices (2008), it already had a robust history at $\mathrm{UCO}$ and was therefore the primary focus of the new office, which not only can promote and manage undergraduate research programs but also can encourage connections between undergraduate research and other high-impact practices. To determine growth in participation, measures of success include the new office's ability to (1) recruit more student and faculty participation in NCUR; (2) increase involvement of selected disciplines (e.g., the humanities) in high-impact practices, including undergraduate research, as reflected in numbers of on-campus Research, Creative, and Scholarly Activities (RCSA) grants; and (3) expand the opportunities to engage students and faculty in undergraduate research abroad. OHIP also has added student-centered features to its operation to achieve these objectives, including the Central Undergraduate Research Board (CURB). Descriptions of the impetus for creating the office and signs of success during its first three years of existence follow.

\section{Moving to Transformative Learning at UCO}

The seed for OHIP was planted in 2005 when UCO began to institutionalize high-impact educational practices, at a time prior to use of the current nomenclature for these practices. UCO began a deliberate process of incorporating core areas, called the central six of transformative learning (TL), into the university's planning and budgeting processes (Barthell et al. 2010). These tenets included (1) cultural and global competencies, (2) disciplinary knowledge, (3) health and wellness, (4) leadership, (5) research, creative, and scholarly activities, and (6) service learning and civic engagement. Parallels can be drawn between practice of these principles and the high-impact educational practices described by Kuh (2008). Several programs on the UCO campus emerged that were consistent with the six tenets and corresponding national trends. For example, research, creative, and scholarly activities became the equivalent of undergraduate research in Kuh's scheme. The Center for Excellence in Teaching and
Transformative Learning (CETTL) was established based on the relationship between teaching and TL. In this way multiple TL reference points formed a network across the campus. Currently, TL practices are incorporated into a badging system. The Student Transformative Learning Record, or STLR, allows students to have a separate record of these high-impact practices available at graduation (Barthell et al. 2014).

The cultural shift integrating the central six TL principles into teaching inside and outside of the classroom contributed to important changes in undergraduate research, which evolved from faculty-driven but student-centered collaboration (Barthell 2012). An important part of this shift was recognition of the benefits of research for both students and faculty. In 2007, the university established the Student Research, Creative, and Scholarly Activities grant program as a conscious effort to provide students with ownership of and engagement in their own projects while conforming to the mission, vision, and long-term goals of the institution. Although faculty in the STEM fields were accustomed to engaging students in research, faculty in other fields were not, and the grants encouraged collaboration between students and faculty mentors in all disciplines. Faculty and staff representing all five colleges on campus served on the Research Advisory Council and the Undergraduate Research and Creative Activities Team (URCAT) and had a key role in developing and implementing the new grant program. The result, validated by all participants, avoided creating an excessively burdensome student funding application process. The mission of the RCSA program is to promote academic transformative learning experiences for students from all disciplines by supporting productive and collaborative engagement with faculty members through research, creative, and scholarly activities. Incorporation of mentoring into faculty tenure and promotion guidelines also has advanced this cultural shift by emphasizing its importance and providing faculty with a tangible benefit for mentoring students.

By its design, the RCSA program places the student in the position of principal investigator; students are encouraged to assume responsibility for research outcomes. This marks an important departure from the previous view of on-campus research funding, which focused on professors as principal investigators. Positive impacts of this change include the facilitation of meaningful discussions between students and mentors about research projects, engagement of students in all aspects of grant writing and planning, and an increase in students' sense of ownership and responsibility for the research or creative activity. Proposals are limited to 1,000 words, in addition to a literature-cited section, detailed budget, and budget justification. Applicants are directed to provide a clear description of their RCSA project by developing their own research questions, identifying original and creative solutions to potential issues

70 Scholarship and Practice of Undergraduate Research 
and problems, gaining a greater appreciation for their discipline by using the library and other academic resources, reading scholarly works and publications, presenting sound methodology, and explaining the significance and value of their project. The goal is to give students real grant-writing experience.

Despite the widespread incorporation of TL (high-impact) practices into academic and social life on the UCO campus and implementation of the RCSA program for students in all disciplines, a disparity in research activities existed among the five respective undergraduate academic colleges. RCSA grant awards from 2007 to 2011, for example, showed higher funding rates in the College of Mathematics and Science (31.7 percent of 309 awards) and College of Education and Professional Studies (37.2 percent), whereas the College of Liberal Arts, the largest credit-hour-producing college on campus, received only 12.6 percent. This difference was attributed to the interest levels of faculty members at the respective colleges. The new office is encouraging more involvement of liberal arts disciplines in undergraduate research. Creating OHIP has moved undergraduate research programs away from the perceived STEM focus and views the programs as part of the larger framework of high-impact, or transformative, teaching practices. The new office can work with other departments and institutions on campus to promote RCSA activities that have a service learning component, or it can work with living learning communities to better integrate undergraduate research into these groups, for example.

\section{Staffing the Office of High-Impact Practices}

Although a need for an office of high-impact practices was identified, resources were limited. To minimize the fiscal impact of initiating OHIP, the office opened with only one and one-half full-time equivalent (FTE) positions. Michael Springer, faculty member in the Department of History and Geography at the College of Liberal Arts, was selected as director, committing half of his time to the office. An added benefit of his appointment was his connection to the College of Liberal Arts, creating an opportunity to raise the profile and promotion of undergraduate research programs there. His hours are consistent with the model used by other campus faculty serving in part-time administrative roles, including department chairpersons and assistant deans. Dana Jackson-Hardwick was hired as the full-time assistant director.

\section{Working with Student and Faculty Advisory Boards}

In addition to the director and assistant director, the faculty and staff serving on URCAT assist the office. This dynamic group is composed of 15 people: two faculty representatives from each of the university's five undergraduate colleges and five additional members, representing the Office of Research and Sponsored Programs, Institutional Review Board, library, faculty senate, and STLR (which offers grants to students and faculty through a Title III grant from the Department of Education). URCAT serves as an undergraduate research advisory board, assesses existing programs, researches and proposes new policies and programs, and reviews submissions for the RCSA grant program. Its members also are a key conduit for communication between the colleges and OHIP, and they help shape undergraduate research experiences at UCO from the faculty and staff perspectives. Although URCAT has existed since 2007, the creation of OHIP led to an expanded purpose for this committee that, in addition to the duties previously described, now includes promotion of undergraduate research among its primary tasks. Aligning this existing committee with OHIP is a budget-neutral way to engage faculty in promoting undergraduate research.

One administrative innovation introduced by OHIP is the Central Undergraduate Research Board. Although URCAT provides faculty and staff with a venue for promoting and enhancing undergraduate research, no similar opportunity for student input existed at UCO. To address this administrative lacuna, OHIP created a new advisory board in 2015 that was composed of students. Following the URCAT model, two student members from each college and the Forensic Science Institute are selected to serve on CURB. Applicants for board positions must have a minimum 2.5 GPA and at least one semester of faculty-mentored research and commit to continuing their own research while serving on the board. Once selected, members select a chair and plan for annual activities and workshops aimed at increasing involvement in research, creative inquiry, and scholarly activities. CURB works with OHIP and URCAT to promote grant programs and provides a sounding board and a space for an open dialogue with students at all stages of the research process. More important, as peer mentors, members of CURB are increasing awareness of and participation among underrepresented and first-generation students and raising the visibility of programs in all colleges on campus. Students apply to serve on the board each year and receive a CURB shirt as compensation as well as food during the meetings, leading to minimal costs for this board.

\section{Expanding Opportunities for Students}

One responsibility of OHIP is to promote participation in undergraduate research events, and one measure of the office's impact is participation in events like Oklahoma Research Day, an annual event showcasing student research from the state's colleges and universities, and the National Conference on Undergraduate Research. UCO routinely sends one of the largest contingents of students in the state to ORD, an event that usually draws about 1,200 participants, and engagement continues to grow (Wohlers et al. 2012). In 2016, for example, 479 students and faculty (first and second presenters) represented UCO, an increase of almost 10 percent from the previous year. 
The largest gains in participation over the last four years have been in the College of Business (41.51 percent) and the College of Fine Arts and Design (69.23 percent). There is continued growth in the number of student presenters at the NCUR (see Figures 1 and 2). A combined 87 students presented at the national conference in 2015 and 2016 (after the inception of OHIP), an average of 43.5 students per year, which is a significant increase from a total of 41 presenters between 2011 and 2014, an average of 10.25 per year. There also are clear gains in participation among students from the College of Liberal Arts and College of Fine Arts and Design over the past two years. In addition to the state and national events, OHIP offers student travel presentation grants to support participation in other professional conferences. The program, which began in 2008, awarded an average of 21 grants per year to students between 2008 and 2012. The new office has increased funding to the program by 30 percent, which allows approximately 30 travel grants to be awarded each year. Taking these figures together, the number of students presenting research at collegiate and professional conferences has increased to more than 500 per year since OHIP began, enhancing the educational experience for students in all disciplines.

OHIP has supported continued growth of the university's RCSA grant program, which has averaged 140 awards per year for the last three years, an increase from an average of 113 per year for the three years prior to the office's creation (see Figure 3). This may be the result of OHIP's work to promote undergraduate research, such as the training sessions for faculty hosted at the Collegium of College Teaching and Practice held each fall and the office's advocacy of the annual Promoting Undergraduate Research Conference sponsored by the Oklahoma Regents for Higher Education, a conference that brings together faculty and administrators from around the state to discuss best practices. Both events provide an important forum to showcase the dynamic models for faculty-mentored, student-centered research on the UCO campus. The RCSA program is an important component of the undergraduate research experience, accounting for 40 percent of student research projects funded by the three primary sources on campus: the RCSA grant program, the research assistantships of the Office of Research and Sponsored Programs funded by faculty on-campus grants, and a new STLR grant program launched in 2014. These three UCO programs provided funding for 356 students working on faculty-mentored research, creative and scholarly activities during academic year 2016-17: OHIP's RCSA grant program awarded 142 grants; the STLR grant program administered by CETTL awarded 139 research, creative, and scholarly activity-related grants; and the Office of Research and Sponsored Programs awarded 75 research assistantships. (The STLR program offers funding for projects related to all central six tenets of transformative
FIGURE 1. Number of UCO Presenters at the National Conference on Undergraduate Research, 2011-2016

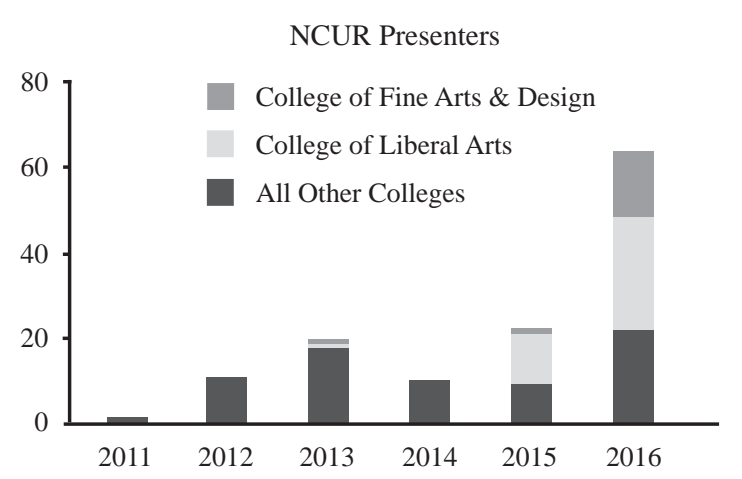

learning. The number provided here represents only projects identified as having a research, creative, or scholarly activity component.)

OHIP also continues to attract new mentors to work with students. Over the past 10 years, 209 instructors have served in this role, accounting for 39 percent of the university's full-time faculty. Over the last five years of the program, one in four professors has mentored an RCSA grant recipient. Moreover, in the last three years, OHIP has recruited 52 new faculty mentors, or an average of just over 17 per year.

\section{Establishing New Initiatives}

The office launched two new programs in 2017 aimed at further increasing and promoting undergraduate research opportunities. An undergraduate research abroad grant program, modeled on the successful RCSA grants, provides support for faculty and students conducting research abroad. Awards include $\$ 6,000$ for travel expenses, an hourly stipend for fall and spring semesters, and a tuition waiver for students. In addition to encouraging undergraduate research, this grant fosters other high-impact practices such as learning communities, global competencies, and cultural competencies. This year also saw the launch of 1890: A Journal of Undergraduate Research, an annual peer-reviewed journal showcasing undergraduate research, scholarly, and creative activities (see Figure 4). Students in the Department of English's editing and publishing course are engaged in all production aspects, such as crafting the call for papers, organizing submissions and sending manuscripts out for review, editing, and designing the journal. The journal's inaugural edition appeared in spring 2017. These new initiatives coincide with growing interest in and support for undergraduate research in all disciplines at the university. This is, in part, the result of OHIP's hard work to raise the profile of this key high-impact practice. It also is the product of planning efforts for NCUR 2018, to be hosted at UCO, which has brought new momentum and focus to UCO undergraduate research. 
FIGURE 2. UCO Participants at NCUR 2016 in Asheville, North Carolina

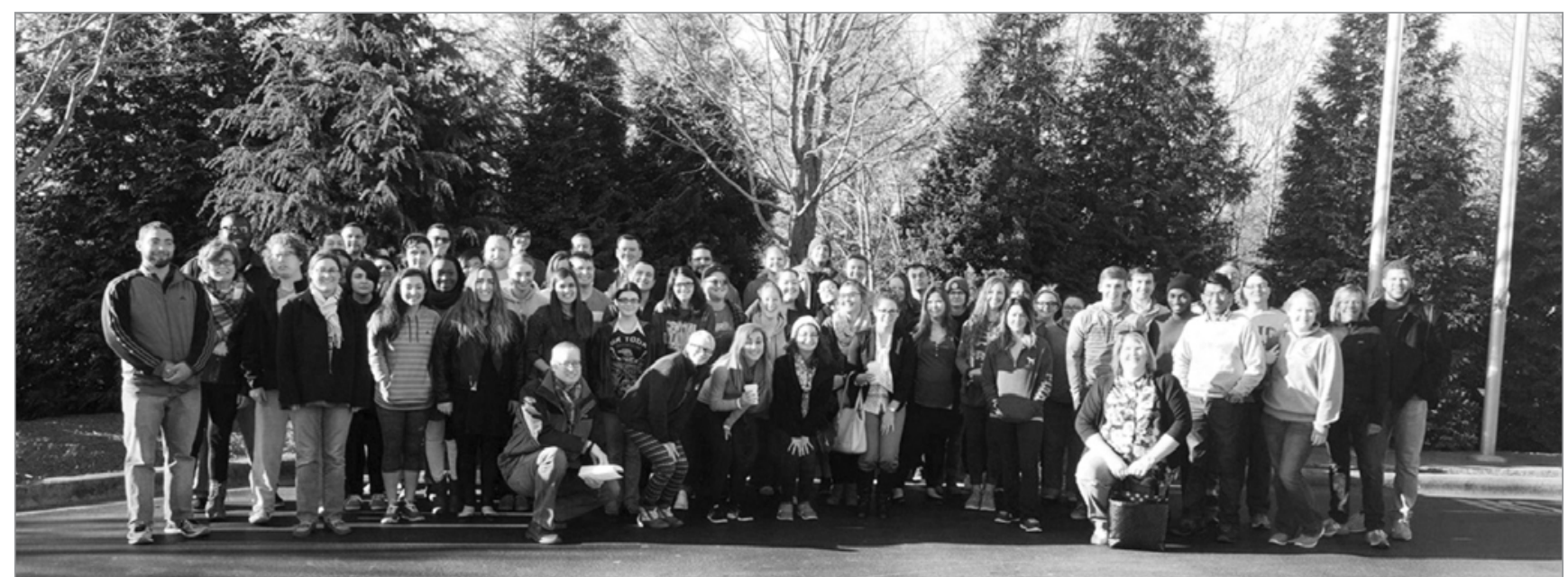

FIGURE 3. RCSA Grants Awarded by Year

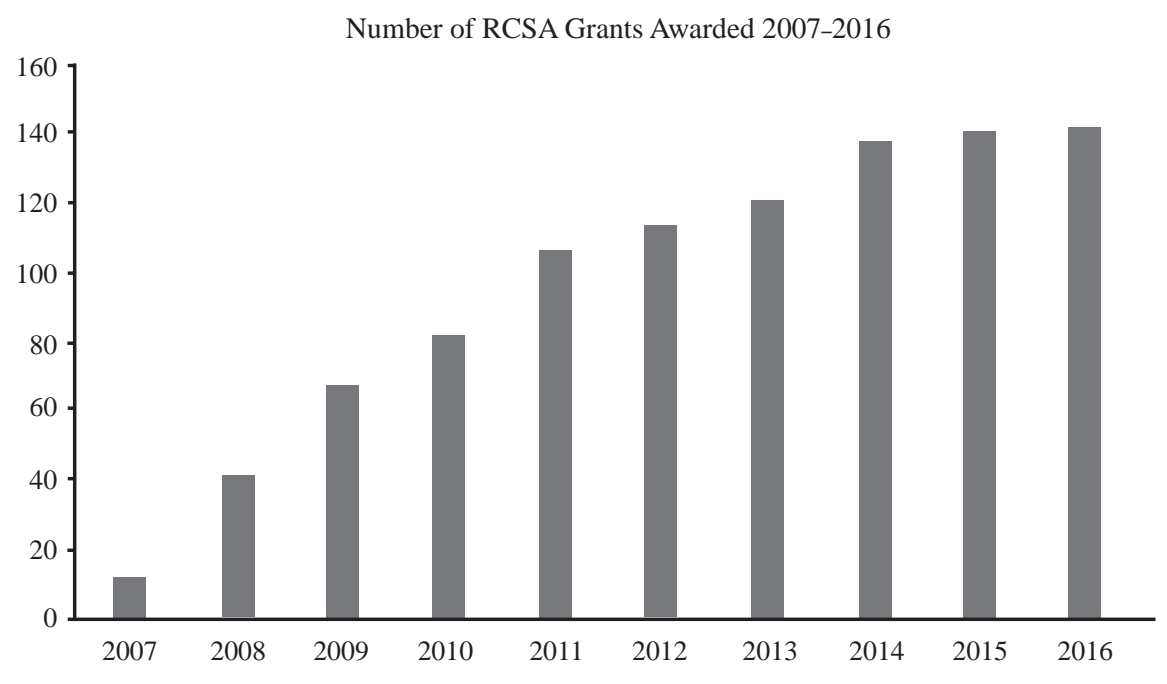

\section{Institutionalizing $\mathrm{OHIP}$}

OHIP cannot function by human ingenuity and enthusiasm alone; it requires financial resources to support the programs it offers. Although there is support from the provost and the president because of the strong return on investment that undergraduate research programs bring, the stark reality of shrinking state appropriations limits the available financial resources. Among the larger expenses associated with the new office is funding the expansion of RCSA and student travel grant programs. In particular, the increased emphasis on NCUR participation resulted in a 191 percent increase in the number of accepted abstracts from UCO students between 2015 and 2016. The university's commitment to fund travel expenses for students accepted to present at this conference led to a similar increase in the program's monetary needs. Although the
RCSA program budget has continued to expand over the past few years, concomitant with the increase in abstract proposals recommended for awards, available funding affects the number of proposals that can be supported by OHIP each year.

Institutionalization of an initiative may begin with limited available funds and follow a return-on-investment model to justify further funding. At UCO, for example, the Center for Undergraduate Research and Education in Science, Technology, Engineering, and Mathematics (CURE-STEM), a faculty-development model focused on student success, began in 2008 with only four faculty members; it has since expanded to include more than 30 faculty members as additional funding became available and the return on investment (as measured by external 
FIGURE 4. Cover of 1890: A Journal of Undergraduate Research. Cover design by Beth Anderson.

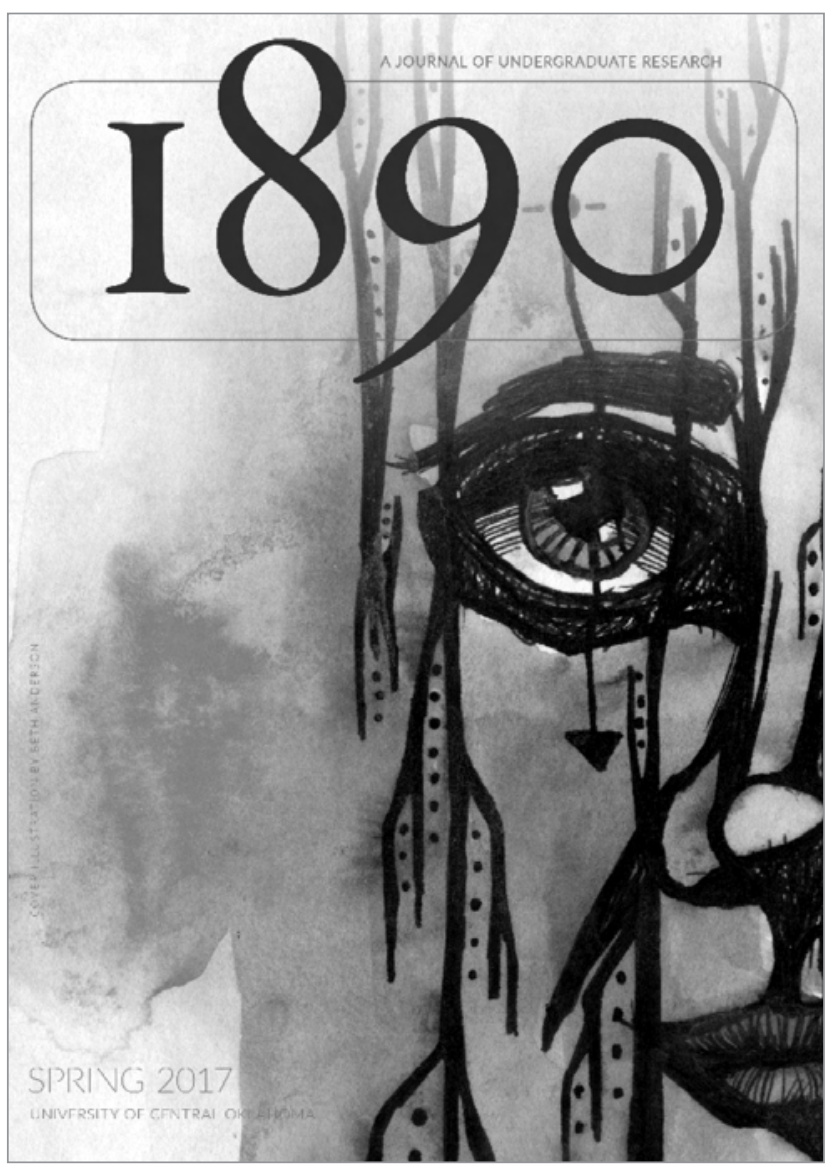

grant funding) exceeded 10 to 1 (Barthell et al. 2013). The RCSA student grant program now has a companion mentor program that compensates faculty mentors. Students enroll in independent study credit hours for their projects, and their mentors receive a stipend paid from the tuition. Alternatively, faculty members may choose to "bank" the hours toward reassignment time from teaching. During the past academic year, the largest group participating in this program has included students and faculty from the College of Fine Arts and Design and College of Liberal Arts. This compensation program is another way to encourage mentorship in undergraduate research by faculty members.

\section{Conclusion}

Although the Office of High-Impact Practices at UCO is new, early signs show its significant impact in expanding the benefits of an undergraduate research model pioneered in STEM fields to students in all disciplines. UCO's office arose from a movement to transformative learning practices that began more than a decade ago. Nevertheless, the university's experience over the past three years points to important considerations for any school wishing to establish a similar office, including assessment of support resources available and engaging both faculty and students in office programming. Increasing participation in undergraduate research experiences by students from all five colleges at UCO indicates OHIP's success in engaging students and increasing opportunities for high-impact learning practices. It also suggests that other campuses may realize similar benefits by expanding from a strictly research-oriented perspective to one that is inclusive of all high-impact practices.

\section{References}

Barthell, John F. 2012. "Faculty-Driven and Student Centered: A Formula for Undergraduate Research During the New Normal." In Characteristics of Excellence in Undergraduate Research (COEUR), ed. Nancy Hensel, 38-40. Washington, DC: Council for Undergraduate Research.

Barthell, John F., Wei R. Chen, Beverly K. Endicott, Charles A. Hughes, William J. Radke, Charlotte K. Simmons, and Gregory M. Wilson. 2013. "Encouraging and Sustaining a Culture of Student-Centered Research at a Predominantly Undergraduate Institution." CUR Quarterly 34(1): 41-47.

Barthell, John F., Ed Cunliff, Katherine Gage, William J. Radke, and Cheryl Steele. 2010. "Transformative Learning: Collaborating to Enhance Student Learning." Proceedings of the 115th Annual Meeting of NCA/The Higher Learning Commission 26: 56-60.

Barthell, John F., Myron Pope, Jeff King, Cia Verschelden, Charles A. Hughes, and Gregory M. Wilson. 2014. "Using a Transformative Learning Transcript to Assess High-Impact Practices." Proceedings of the 119th Annual Meeting of NCA/The Higher Learning Commission 30: 58-63.

Bauer, Karen, and Joan S. Bennett. 2003. "Alumni Perceptions Used to Assess Undergraduate Research Experience." Journal of Higher Education 74: 210-230. doi:10.1353/jhe.2003.0011

Brownell, Jayne E., and Lynn E. Swaner. 2009. "High-Impact Practices: Applying the Learning Outcomes Literature to the Development of Successful Campus Programs." Peer Review 11(2): 26-30.

Corley, Christopher R. 2013. "Mentoring to Collaborating: Fostering Undergraduate Research in History." History Teacher 46: 397-414.

Dean, James M., and Melanie L. Kaiser. 2010. "Faculty-Student Collaborative Research in Humanities." CUR Quarterly 30(3): $43-47$.

DeLoach, Stephen B., Elizabeth Perry-Sizemore, and Mary O. Borg. 2012. "Creating Quality Undergraduate Research Programs in Economics: How, When, Where (and Why)." American Economist 57: 96-110. doi: 10.1177/056943451205700108

DeVries, David N. 2001. "Undergraduate Research in the Humanities: An Oxymoron." CUR Quarterly 21(4): 153-155.

Ehrenberg, Ronald G. 2005. "Involving Undergraduates in Research to Encourage Them to Undertake Ph.D. Study in Economics." American Economic Review 95: 184-188. doi: $10.1257 / 000282805774669772$

74 Scholarship and Practice of Undergraduate Research 
Gagliardi, Johnathan S., Rebecca R. Martin, Kathleen Wise, and Charles Blaich. 2015. "The System Effect: Scaling HighImpact Practices Across Campuses." In Enhancing and Expanding Undergraduate Research: A Systems Approach, ed. Mitchell Malachowski, Jeffrey M. Osborn, Kerry K. Karukstis, and Elizabeth L. Ambos, 15-26. San Francisco: Jossey-Bass. doi: 10.1002/he.20119

Kuh, George D. 2008. High-Impact Educational Practices: What They Are, Who Has Access to Them and Why They Matter. Washington, DC: Association of American Colleges and Universities.

Lopatto, David. 2010. "Undergraduate Research as a HighImpact Student Experience.” Peer Review 12(2): 27-30.

Malachowski, Mitchell. 1999. "Promoting Undergraduate Research in Non-Science Areas at Predominantly Undergraduate Institutions." CUR Quarterly 19(3): 126-130.

Malachowski, Mitchell, Jeffrey M. Osborn, Kerry K. Karukstis, Elizabeth L. Ambos, Shontay L. Kincaid, and Daniel Weiler. 2015. "Fostering Undergraduate Research Change at the System and Consortium Level: Perspectives from the Council on Undergraduate Research." In Enhancing and Expanding Undergraduate Research: A Systems Approach, ed. Mitchell Malachowski, Jeffrey M. Osborn, Kerry K. Karukstis, and Elizabeth L. Ambos, 95-106. San Francisco: Jossey-Bass. doi: 10.1002/he.20126

McDorman, Todd. 2004. "Promoting Undergraduate Research in the Humanities: Three Collaborative Approaches." CUR Quarterly 25(1): 39-42.

Rogers, V. Daniel. 2003. "Surviving the 'Culture Shock' of Undergraduate Research." CUR Quarterly 23(3): 132-135.

Wohlers, Tony. E., Gregory. M. Wilson, S. Narasinga Rao, Lori Gwyn, Kathryn Schoonover-Redden, and Jerry R. Malayer. 2012. "Celebrating Undergraduate Research in Oklahoma: the History and Impact of Statewide Undergraduate Research Conferences." CUR Quarterly 32(4): 15-20.

\section{Michael S. Springer}

University of Central Oklahoma, mspringer@uco.edu

Michael S. Springer is history professor and director of the Office of High-Impact Practices at the University of
Central Oklahoma. He serves as a CUR Councilor and has directed OHIP since its inception in 2014, overseeing the office's programs and developing new initiatives to broaden participation in undergraduate research and creative activities.

John F. Barthell is provost and vice-president for academic affairs at UCO. He also serves as a CUR Councilor. Barthell, the former dean of UCO's College of Mathematics and Science, oversaw the development of the Center for Undergraduate Research and Education in STEM fields (CURE-STEM) and the Transformative Learning Scholars program at UCO.

Charlotte K. Simmons is associate vice-provost for academic affairs and former dean and associate dean of the College of Mathematics and Science at UCO. She provides oversight of the Office of High-Impact Practices budget and the Transformative Learning Scholars program. Simmons, a CUR Councilor, has served as the principal investigator or project coordinator on several NSF grants in support of undergraduate research.

Dana Jackson-Hardwick is assistant director of the Office of High-Impact Practices at UCO. She earned an MA in history from UCO and served as assistant archivist specializing in government information at the university library. She administers the Research, Creative, and Scholarly Activities grant program and works with the students on the Central Undergraduate Research Board to promote undergraduate research.

Gregory M. Wilson is assistant vice-president of the Office of Research and Sponsored Programs at UCO. He remains active in research and is a CUR Councilor. Wilson works in conjunction with the provost to provide oversight of external funding and on-campus grant and research assistantship awards at the university. 